\title{
A Questionnaire-based Study on Chinese University Students' Demotivation to Learn English
}

\author{
Chili $\mathrm{Li}^{1} \&$ Ting $\mathrm{Zhou}^{2}$ \\ ${ }^{1}$ School of Foreign Languages, Hubei University of Technology, Wuhan, Hubei, China \\ ${ }^{2}$ School of Foreign Languages, Inner Mongolia University of Technology, Hohhot, Inner Mongolia, China \\ Correspondence: Chili Li, School of Foreign Languages, Hubei University of Technology, 28\#, Nanli Road, \\ Hongshan District, Wuhan, Hubei Province, China. E-mail: sundaylcl@126.com
}

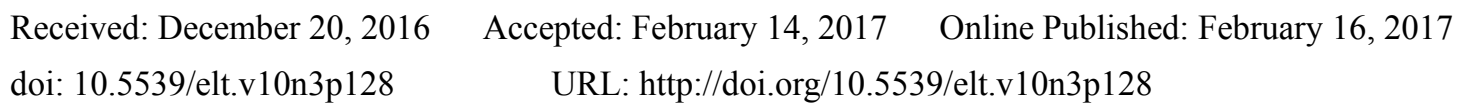

\begin{abstract}
This paper, adopting questionnaire survey method, investigated 367 non-key local university English as a Foreign Language (EFL) students' demotivation to learn English. The collected data revealed that there were two main categories of demotivators: internal factors (lack of intrinsic interest, experience of failure and lack of confidence, and unclear study goal) and external factors (teaching material, teaching process and teaching content, significant others, teachers' teaching competence and attitude of teachers, the relationship between teachers and students, teaching facilities and teaching environment). External factors are found to be more influential than internal ones in the participants' demotivation to learn English. The current study adds to the literature in that unclear study goal is an important demotivator in Chinese local non-key university EFL students' English study. The findings of this study will enrich the research of demotivation to learn English, and to provide an empirical basis for the needs analysis in English class and curriculum reform, as well as to provide reference for implementing central and local education policies.
\end{abstract}

Keywords: Chinese university students, demotivation to learn English, questionnaire

\section{Introduction}

Research on demotivation has been the foci in second language acquisition in recent decades. Researchers from the west (i.e., Chambers, 1993; Dornyei, 2001; Oxford, 1998) and Asia (i.e., Sakai \& Kikuchi, 2009; Trang \& Baldauf, 2007) have shown great interest in this topic. Compared to studies on demotivation abroad, research in China started a bit late, but developed fast (i.e., Hu \& Cai, 2010; Zhou \& Wang, 2012). These studies have generated deep insight into demotivation to learn English. However, they mainly focused on the demotivation of students from the key universities. Little is known about those students studying English at non-key local universities. Compared with those key universities who enjoy better financial support from government at all levels with more expertise teachers and better teaching resources, non-key local universities in Mainland China, while in their effort to transforming themselves into application-oriented higher education institutions, are confronted with such constraints as teaching hours for College English programmes being dramatically reduced, limited expertise of English teachers, and others. Students at local universities thus are more likely to be demotivated in their English study. Therefore, this paper aims to investigate the factors that might have caused demotivation to learn English among local university students. The findings will be implicative for teachers to take remedial measures to reduce the detrimental effects of demotivation in English class.

\section{Research Background}

Demotivation is the external force, which may make people reduce or lose a certain behavior tendency or the conduct of behavior (Dornyei, 2001). This definition focused on the external factors and was criticized for failing to take into account the internal factors. However, later empirical studies showed that, in addition to the external factors, the internal factors might also cause motivation recession (Zhou \& Wang, 2012). This paper holds that demotivation is a phenomenon of students' lack of motivation to study English as a result of both external and internal factors.

Empirical studies in the West initated in early 1990s. Gorham and Christophel (1992) conducted a questionnaire survey on 308 students to identify the factors that might have brought about demotivation. They discovered three 
demotivators: context, structure, and teachers. Among the three factors, teacher-related reasons were found to be the most influential demotivator. Chambers (1993) conducted a questionnaire survey on 191 students and 7 teachers in four middle schools in the UK for identifying the reasons for the students' demotivation to learn English. The results suggested that some teacher behaviors such as unclear lecture and sarcastic language used by teachers in class might have caused demotivation among the students.

Oxford (1998) asked 250 university students in the United States to look back to their English learning experiences by writing a retrospective journal, and paid special attention to the role of teachers. The results showed that the demotivation factors mainly centred on four aspects: (1) inharmonious relationship between teachers and students; (2) the negative attitude of the teachers towards the curriculum and the teaching materials; (3) incompatibility of the styles between teachers and students; (4) the unreasonableness in designing and using the class activities. This study identified teacher-related demotivators, but paid little attention to other demotivational factors.

Dornyei (2001) summed up nine demotivating factors by coding the results of semi-structured interviews: teachers, the incompleteness of the school educational administration, the recession of self-confidence, the negative attitudes towards the second language, the coerciveness of the second language course, negative transfer in the second language acquisition, negative attitude toward learning the second language, the attitude towards other students, and teaching materials. The teacher factor accounts for $40 \%$ of the overall demotivating factors. These nine demotivators laid a solid foundation for later studies on demotivation. This study examined demotivators from the perspective demotivated students, which might generate a misunderstanding that demotivation only belongs to the demotivated learners. In fact, demotivation has been found to be prevalent among all learners.

Demotivation in foreign language classroom has also recently drawn attention from Asian researchers. Trang \& Baldauf (2007) investigated the demotivators in Vietnamese students' English study. They found that $88 \%$ of the surveyed students had or were experiencing a weakening of the learning motivation; and that the factors resulting in demotivation can be divided into internal factors (36\%) and external factors (64\%). Sakai \& Kikuchi (2009) reported a survey on demotivation among 656 Japanese high school students. They found out five demotivation factors: learning content and materials, teachers' competence and teaching style, inadequate school facilities, lack of intrinsic motivation, and test scores. Kim (2015) interviewed 29 Korean college students to identify the demotivators in their study of English and obtained three demotivational factors including lack of meaningful purpose, lack of improvement and success experiences, and lack of self-determination. Hassaskhah, Zafarghandi \& Fazeli (2015) administered a questionnaire survey to 308 Iranian English major students and found that the demotivators are at such levels as institution, important others, and self.

Compared to research on demotivation in the west, studies on this phenomenon in China started a bit late after 2000. Hu and Cai (2010) first interviewed some students who had demotivation in English learning and conducted a questionnaire survey for 16 English teachers and 170 non-English majors. They identified six demotivators (learning interest, learning goal, valence, anxiety, attribution, learning environment). Zhou and Wang (2012) made a questionnaire survey for 766 College English learners. They found that the main factors affecting the learning motivation could be divided into five major categories, including 2 internal factors (lack of intrinsic interest, lack of effective learning strategy) and 3 external factors (teachers' competence and teaching style, curriculum and learning material, defective teaching attachments). Li (2013) investigated the internal factors triggering Chinese college EFL learners' demotivation and identified the following demotivators such as decrease in self confidence, insufficiency in affective cognition, learning strategies deficiency, and lack of intrinsic interest. Sun \& Lei (2013) found teacher-related factors, teaching contents, student-related factors, and teaching environment are the four major demotivators in Chinese EFL classrooms, among which teacher-related factors are the most influential.

A further examination over the relevant literuatre reveals that present studies on demotivation in China mainly focused on students from key universities, and that there is paucity of research on demotivation among students from non-key local institutions. It is therefore necessary to further study demotivation among students from these local universities (Li, 2014).

\section{Research Design}

\subsection{Research Questions}

1) Do the students from local non-key universities experience demotivation?

2) What factors might have caused demotivation? 


\subsection{Participants}

The participants were 367 students from a non-key local university. Of these participants, there were 182 male students and 185 female students. 223 of the participants were freshmen, 66 sophomores, 70 juniors and 8 seniors respectively. They were majoring in English, Material Science, Financial Management, Urban Design, Electrical Engineering, Law, and so on.

\subsection{Research Instrument}

The questionnaire used for this study is composed of two parts. The first part was to investigate the participants' background information including grade, major, gender, hometown, and English learning enthusiasm. The second part was designed based on previous studies. This section has 46 items of statement, taking the form of Five-Likert scale. The numbers 1, 2, 3, 4, 5 represent "strongly disagree, disagree, neither agree nor disagree, agree, and strongly agree" respectively. The Cronbach $\alpha$ of the questionnaire is 0.948 , which indicates that the questionnaire has a high reliability.

\subsection{Data Collection and Analysis}

Before the questionnaire survey was administered, the participants were told about the research purposes of this investigation. 378 copies of the questionnaires were collected, of which 11 ones were invalid and thus were excluded. That is, 367 questionnaires were valid for the current study. The collected questionnaires were first computed into SPSS 22.0 and then processed by means of descriptive analysis. In order to identify the demotivators, factor analysis was conducted.

\section{Results and Discussion}

\subsection{Answers to Research Question 1}

The first research question asks whether the students from local non-key universities experience demotivation in their English study.

Table 1. Descriptive analysis of the questionnaire data $(\mathrm{N}=367)$

\begin{tabular}{|c|c|c|c|c|c|c|c|c|c|}
\hline Item & Min & Max & Mean & SD & Item & Min & Max & Mean & SD \\
\hline 29 & 1.00 & 5.00 & 3.36 & 1.105 & 1 & 1.00 & 5.00 & 2.62 & 1.165 \\
\hline 27 & 1.00 & 5.00 & 3.28 & 1.108 & 14 & 1.00 & 5.00 & 2.59 & 1.137 \\
\hline 9 & 1.00 & 5.00 & 3.25 & 1.197 & 20 & 1.00 & 5.00 & 2.59 & 1.100 \\
\hline 45 & 1.00 & 5.00 & 3.17 & 1.261 & 39 & 1.00 & 5.00 & 2.59 & 1.028 \\
\hline 8 & 1.00 & 5.00 & 3.16 & 1.134 & 11 & 1.00 & 5.00 & 2.57 & 1.246 \\
\hline 2 & 1.00 & 5.00 & 3.13 & 1.113 & 15 & 1.00 & 5.00 & 2.52 & 1.111 \\
\hline 5 & 1.00 & 5.00 & 3.07 & 1.078 & 33 & 1.00 & 5.00 & 2.50 & 1.029 \\
\hline 4 & 1.00 & 5.00 & 3.04 & 1.081 & 21 & 1.00 & 5.00 & 2.49 & 1.063 \\
\hline 28 & 1.00 & 5.00 & 3.01 & 1.053 & 23 & 1.00 & 5.00 & 2.47 & 1.042 \\
\hline 26 & 1.00 & 5.00 & 2.96 & 1.090 & 24 & 1.00 & 5.00 & 2.46 & 1.023 \\
\hline 7 & 1.00 & 5.00 & 2.95 & 1.101 & 38 & 1.00 & 5.00 & 2.44 & 1.022 \\
\hline 13 & 1.00 & 5.00 & 2.95 & 1.109 & 12 & 1.00 & 5.00 & 2.43 & 1.035 \\
\hline 25 & 1.00 & 5.00 & 2.92 & 1.066 & 41 & 1.00 & 5.00 & 2.42 & 1.076 \\
\hline 34 & 1.00 & 5.00 & 2.91 & 1.130 & 44 & 1.00 & 5.00 & 2.42 & 1.135 \\
\hline 6 & 1.00 & 5.00 & 2.89 & 1.083 & 40 & 1.00 & 5.00 & 2.38 & 1.048 \\
\hline 46 & 1.00 & 5.00 & 2.88 & 1.172 & 22 & 1.00 & 5.00 & 2.34 & 1.040 \\
\hline 31 & 1.00 & 5.00 & 2.78 & 1.069 & 42 & 1.00 & 5.00 & 2.33 & 1.102 \\
\hline 19 & 1.00 & 5.00 & 2.74 & 1.138 & 43 & 1.00 & 5.00 & 2.32 & 1.066 \\
\hline 32 & 1.00 & 5.00 & 2.74 & 1.103 & 16 & 1.00 & 5.00 & 2.30 & 1.037 \\
\hline 10 & 1.00 & 5.00 & 2.67 & 1.210 & 18 & 1.00 & 5.00 & 2.30 & 1.010 \\
\hline 35 & 1.00 & 5.00 & 2.67 & 1.131 & 30 & 1.00 & 5.00 & 2.30 & 1.085 \\
\hline 17 & 1.00 & 5.00 & 2.66 & 1.130 & 37 & 1.00 & 5.00 & 2.30 & 1.159 \\
\hline 36 & 1.00 & 5.00 & 2.66 & 1.061 & 3 & 1.00 & 5.00 & 2.27 & 1.021 \\
\hline
\end{tabular}


The collected data showed that 87 (23.7\%) and $222(60.5 \%)$ of the 367 participants clearly expressed that they had little or moderate enthusiasm for learning English respectively, while only $58(15.8 \%)$ had a high enthusiasm for English learning. In order to further understand the features of these participants' demotivation, the collected data were further analyzed through descriptive means (Table 1). The data show that there are 31 items whose mean values are above 2.5 while there are only 15 items whose mean values are less than 2.5 . This finding indicates that the participants were influenced by these demotivators in their English study. According to Li (2013) and Zhou \& Wang (2012), the above result suggests that demotivation is a common phenomenon among students in local universities. This finding is consistent with the relevant literature that demotivation is prevalent among Chinese EFL learners.

\subsection{Answers to Research Question 2}

The second research question examines the factors that might lead to demotivation among the participants. To answer this question, factor analysis was performed. The questionnaire analysis reveals that the questionnaire data are suitable for factor analysis (chi-square $=9201.837 ; \mathrm{P}=.000 ; \mathrm{KMO}=0.934$, close to 1.0 ). By using Principal Component Analysis and setting the factor loadings and communalities lower than .400 , the factor analysis with varimax rotation produced 8 factors with eigenvalues greater than 1.0 (Table 2), which explained $61.695 \%$ of the total variance. The coefficients of the 8 factors are among the range of $0.657-0.882$.

Table 2. Analysis of variance and reliability of all factors explained

\begin{tabular}{lllll}
\hline Factor & \multicolumn{2}{l}{ Rotation Sums of Squared Loadings } & coefficient \\
\cline { 2 - 4 } & Total & \% of Variance & Cumulative \% & \\
\hline 1 & 4.866 & 10.814 & 10.814 & .870 \\
2 & 4.697 & 10.438 & 21.252 & .882 \\
3 & 4.426 & 9.835 & 31.088 & .856 \\
4 & 3.351 & 7.447 & 38.534 & .875 \\
5 & 3.091 & 6.869 & 45.404 & .825 \\
6 & 2.817 & 6.261 & 51.664 & .842 \\
7 & 2.312 & 5.138 & 56.802 & .657 \\
8 & 2.202 & 4.893 & 61.695 & .705 \\
\hline
\end{tabular}

Table 3 reports the loadings of the first five factors. Factor 1 contains 9 variables (Item 2, 4, 25, 26, 27, 28, 29, $30,45)$, involving the curriculum evaluation means, teaching content and teaching materials, etc. It shows that the difficulty of teaching materials and the monotonous teaching method might have made students lose passion for learning English. In addition, the traditoanl teaching mode applied during teaching failed to generate students' interest in English class and thus might lead to demotivation among them. Therefore, Factor 1 is named as "teaching material, teaching content and teaching process". This echoes Kikuchi (2009) that the teaching mode is the inducement of demotivation.

Factor 2 involves 8 variables (Item 38, 39, 40, 41, 42, 43, 44, 46). These items reveal that, due to the negative influence of those people with limited English proficiency, the participants might be reluctant to try their best to learn English. Besides, with the over-emphasis of the importance of English from parents and/or teachers, students might also be unwilling to learn English. Therefore, Factor 2 was named as "significant others". This verifies Kim \& Seo (2012) that the over-emphasis of the importance of English learning from other people around will induce demotivation among students.

Factor 3 encompasses 5 variables (Item 15, 16, 17, 18, 19), involving teaching methods, teaching experience, teachers' lesson preparation before class. So, it is named as "teaching competence and attitude of teachers". This result echos Liang (2008) that inappropriate teaching method might make students lose interest in learning English. Factor 4 contains 5 variables (Item 20, 21, 22, 23, 24). These items indicate that the way teachers interact with students might exert a great impact on students' English learning. It is thus named as "the relationship between teachers and students". Factor 3 and Factor 4 suggest that teacher-related factors might be responsible for EFL learners' demotivation in learning English, which is in line with Gorham \& Christophel (1992) and Dornyei (2001). 
Table 3. Rotated factor loadings of the external factors

\begin{tabular}{lc}
\hline Item & Factor load \\
\hline Factor 1: teaching material, teaching process and teaching content & \\
\hline 27. It is boring to test students only by exam. & .789 \\
30. It is boring to only listen to teachers in class. & .651 \\
28. English teaching pays too much attention to grammar. & .642 \\
29. It is boring for us to remember so many words. & .626 \\
45. We are only taught dumb English in universities. & .624 \\
25. Teaching materials are not close to our life. & .621 \\
26. There are too many new words in our textbooks. & .599 \\
4. Exercises are not interesting. & .499 \\
2. It is boring that teachers only focus on the textbook. & .488
\end{tabular}

\section{Factor 2: significant others}

43. That people with a poor command of English still achieve success negatively affects me. $\quad .814$

42. I do not want to learn English because it makes little help for my future career. $\quad .765$

41. English becomes less important because of the reform of the National Matriculation English. $\quad .748$

44. It is rare to use English in our daily life so that English is not so important. $\quad .740$

40. My parents and families often tell me how important English is, which makes me frustrated. $\quad .599$

39. I lost my confidence by being compared with other peers. $\quad .596$

38. My parents do not give me praise when I make progress.

46. English is not paid with due attention in technological universities. $\quad .468$

\section{Factor 3: teaching competence and attitude of teachers}

17. Teaching method is outdated and cannot satisfy the needs of students.

16. Teachers are inexperienced in teaching.

18. Teachers are not well prepared for their class.

19. Teachers have little interaction with students in class.

15. The high frequency to change teachers makes students uncomfortable.

\section{Factor 4: the relationship between teachers and students}

24. My English teacher criticized me when I did not well in the study.

22. There is not a harmonious relationship between teachers and students.

23. My English teacher do not give me some good suggestions.

20. Teachers show preferences to those who are good at learning English.

21. Teachers are not easy going.

\section{Factor 5: teaching facilities and teaching environment}

35. I am frustrated to be placed into different classes according to my English scores.

32. The overcrowded classroom made me less interested in learning English.

36. I am frustrated when my English scores are posted in public.

34. Teachers cannot take all students into consideration in the large class.

37. English class is often shifted due to conflicts with other courses. 
Factor 5 contains seven variables (Item 31, 32, 33, 34, 35, 36, 37), involving teaching equipment, large class teaching, etc. It is named as "teaching facilities and teaching environment". This shows that the quality of teaching environment might affect students' learning attitude and enthusiasm towards English study. A good environment and atmosphere might make one feel more pleasant both in mind and in body. Therefore, the allocation of teaching facilities and continuous improvement of the teaching environment are the primary matter that the relevant departments and agencies should actively deal with. These above 5 factors belong to the external influence factors.

Table 4 presents the loadings of the last three factors. Factor 6 includes 4 variables (Item 1, 10, 11, 14). These four items are related with the participants' interst in learning English. They suggested that a lack of interest in English study might lead to demotivation. Therefore, Factor 6 is named as "lack of intrinsic interest". This factor is implicative for educators and teachers in that they should first cultivate students' interest. Only when students have the interest in learning, can they have strong motivation to learn English.

Factor 7 contains 4 variables (Item 3, 5, 6, 12), involving the students' experiences and confidence in learning English. It is thus named as "experiences of failure and lack of confidence". This shows that the difficulties in learning English may result in students' failure in achieving success which may reduce their confidence in learning it well and thus trigger demotivation. It is consistent with the findings of the research conducted by Hamada (2011).

Factor 8 contains 3 variables, including Item 7, 8, 9, which are associated with students' unclear learning objectives. Thus, this factor is named as "unclear study goal". It is worth attention that if students do not have a clear goal in their English study, their energies would be likely dispersed due to the temptation of the surroundings. Therefore, it is important for educators to make the students clear about their study goal. For learners, the goal is not only to play a leading role, but also to promote learning.

These three factors (Factor 6, 7,8) are related to the participants themselves. Thus, they are categorized as the internal factors. Based on the results of the study, the external factors account for $62.5 \%$ of the demotivators identified, while the internal factors only accupy $37.5 \%$. This result is consistent with previous research (Gorham \& Christophel, 1992; Trang \& Baldauf, 2007). It might be concluded that the Chinese EFL learners tend to be more strongly motivated by external factors in their English study.

Table 4. Rotated factor loadings of the internal factors

\begin{tabular}{lc}
\hline Item & Factor load \\
\hline Factor 6: lack of intrinsic interest & .822 \\
\hline 11. I am not interested in English. & .733 \\
10. I learn English because it is required by our school but not because of my interest. & .705 \\
14. English learning is a burden to me. & .450 \\
1. My poor English made me demotivated to learn it. & \\
\hline Factor 7: experiences of failure and lack of confidence & .650 \\
\hline 5. It is difficult to understand some long and difficult sentences. & .587 \\
12. I have made so many efforts to learn English but actually it doesn't make senses. & .575 \\
3. It is difficult for me to understand some learning content. & .558 \\
6. I cannot achieve an ideal mark in tests. & .725 \\
\hline Factor 8: unclear study goal & .695 \\
\hline 7. Too many extracurricular activities influenced my English study. & .587 \\
8. I am inclined to be influenced by peers when they do not study hard. & \\
9. I am not motivated to learning English well because of unclear study target.
\end{tabular}

\section{Conclusion}

This study investigated the demotivators among Chinese EFL students from local non-key universities by using questionnaires. It found two types of factors which include eight demotivators: external factors (teaching 
material, teaching process and teaching content, significant others, teachers' teaching competence and attitude of teachers, the relationship between teachers and students, teaching facilities and teaching environment) and internal factors (lack of intrinsic interest, experience of failure and lack of confidence, and unclear study goal). External factors are found to be more influential than internal ones in the participants' demotivation to learn English. What makes this study distinctive from previous studies is in that unclear study goal is found to be an important demotivator.

The findings of this study are implicative for English language teaching. For example, teachers need to pay attention to the teaching methods they apply into their English class so that students could be motivated. In addition, as unclear study goal is found to be an important demotivator, it is necessary for teachers to cultivate students' belief about the benefit of participating in extracurricular activities for English study so that the students come to generate interest in English learning (Li \& Ruan, 2015). An interest in English and English class would help students become clear about their goal and maintain their efforts in learning English.

Although this research has identified eight factors of English learning demotivation, there are some deficiencies. It is cautioned to generalize the results of this study because only questionnaire alone is used. Other methods like interviews and journals are recommended for triangulation in future research.

\section{Acknowledgments}

This study is supported by The Eighth Batch of China Foreign Language Education Fund (ZGWYJYJJ2016B54), Chinese University Research Projects of Foreign Language Instruction (2016HB0051A), Doctoral Research Start-up Fund of Hubei University of Technology (BSQD14062).

\section{References}

Chambers, G. (1993). Taking the 'De' out of Demotivation. Language Learning Journal, 7, 13-16. https://doi.org/10.1080/09571739385200051

Dörnyei, Z. (2001). Teaching and Researching Motivation. Harlow: Longman.

Gorham, J., \& Christophel, D. M. (1992). Students' Perception of Teacher Behaviors as Motivating and Demotivating Factors in College Classes. Communication Quarterly, 40(3), 239-252. https://doi.org/10.1080/01463379209369839

Hamada, Y. (2011). Different demotivators for Japanese junior high and high school learners. Journal of Pan-Pacific Association of Applied Linguistics, 15(1), 15-38.

Hassaskhah, J., Zafarghandi, A. M., \& Fazeli, M. (2015). Reasons for demotivation across years of study: voices from Iranian English major students. Educational Psychology, 33(5), 557-577. https://doi.org/10.1080/01443410.2014.893557

Hu, W., \& Cai, J. (2010). Construction of Model of Demotivation in English Learning. Foreign Language Education, 31(3), 41-49.

Kikuchi, K. (2009). Listening to our leaner' voice: what demotivates Japanese high school students? Language Teaching Research, 13(1), 103-120.

Kim, S. (2015). Demotivation and L2 motivational self of Korean college students. English Teaching, 70(1), 29-55. https://doi.org/10.15858/engtea.70.1.201503.29

Kim, T. Y., \& Seo, H. S. (2012). Elementary School Students' Foreign Language Learning Demotivation: A Mixed Methods Study of Korean EFL Context. The Asia-Pacific Education Researcher, 21(1), 160-171.

Li, C. (2014). A Brief Analysis of the Research on the Negative Motivation of English Language Learning in China. Journal of Anhui University of Technology (Social Science), 31(6), 93-94.

Li, C., \& Ruan, Z. (2015). Changes in beliefs about language learning among Chinese EAP learners in an EMI context in Mainland China: A socio-cultural perspective. System, 55, 43-52. https://doi.org/10.1016/j.system.2015.08.010

Li, L. (2013). A Study on Internal Factors of Chinese College EFL Learners' Demotivation. Journal of PLA University of Foreign Languages, 36(2), 65-69.

Liang, L. (2008). Study of Demotivation in English Classroom. Journal of Tianjin University of Technology and Education, 18(3), 75-78.

Oxford, R. L. (1998). The unraveling tapestry: Teacher and course characteristics associated with demotivation in the language classroom. Demotivation in foreign language learning. Paper presented at the TESOL'98 
Congress, Seattle, WA.

Sakai, H., \& Kikuchi, K. (2009). An Analysis of Demotivators in the EFL Classroom. System, 37(1), 57-69. https://doi.org/10.1016/j.system.2008.09.005

Sun, Y. M., \& Lei, L. (2013). An analysis of demotivators in Chinese college EFL classrooms. Foreign Languages Research, 5, 57-65.

Trang, T. T. T., \& Baldauf, Jr. R. B. (2007). Demotivation: Understanding Resistance to English Language Learning - The Case of Vietnamese Students. The Journal of Asia TEFL, 4(1), 79-105.

Zhou, C., \& Wang, W. (2012). Demotivators Analysis of Chinese University EFL Learners. Foreign Languages in China, $9(1), 48-55$.

\section{Copyrights}

Copyright for this article is retained by the author(s), with first publication rights granted to the journal.

This is an open-access article distributed under the terms and conditions of the Creative Commons Attribution license (http://creativecommons.org/licenses/by/4.0/). 